\title{
EVOLUÇÃO DO DESEMPENHO DOS TRANSPORTADORES DE CORREIA DA PELOTIZAÇÃO SUPORTADO PELA GESTÃO DE ATIVO E ENGENHARIA DE CONFIABILIDADE*
}

Ivo Sebastião Costa e Silva'

\section{Resumo}

Estamos extraindo o maior valor dos nossos ativos? Temos resposta por meio de análise de confiabilidade e o resultado atingido com a implementação de práticas de gestão de ativos. Nas usinas de Pelotização da Vale foi aplicada uma estratégia de manutenção voltada para o negócio e nos últimos dois anos (2015 e 2016), houve a redução de $21 \%$ do gasto anual com correia transportadora e $28 \%$ do valor de estoque desse item. Através da engenharia de confiabilidade, com análise de degradação das correias e análises dos dados de vida é possível identificar o momento ótimo para troca da correia e definir um estoque com base em risco, que é o ponto de maior resultado operacional.

Palavras-chave: Gestão de Ativos; Engenharia de Confiabilidade; Transportador de Coreia.

\section{PERFORMANCE EVOLUTION OF BELT CONVEYOR SUPPORTED BY ASSET MANAGEMENT AND RELIABILITY ENGINEERING}

\begin{abstract}
Are we extracting the highest value from our assets? This question can be answered through reliability analysis and the result achieved with the implementation of asset management practices. At the Vale Pelletizing plants, a business-oriented maintenance strategy was applied and in the last two years (2015 and 2016), the annual cost of the conveyor belt was reduced by $21 \%$, the inventory value of this item decreased by $28 \%$. Through reliability engineering, belt degradation analysis and life data analysis, it is possible to identify the optimum moment for belt change and to define a stock based on risk, which is the point of greatest operating result.
\end{abstract}

Keywords: Asset Management; Reliability Engineering; Belt Conveyor.

1 Engenheiro mecânico com ênfase em mecatrônica, MBA Gestão de Projetos, Engenheiro de manutenção especialista em transportador de correia, Engenharia de manutenção da Pelotização, Vale. 


\section{INTRODUÇÃO}

A Vale possui no Brasil um total de 11 (onze) usinas de pelotização, sendo 8 (oito) delas no Espirito Santo, 2 (duas) em Minas Gerais e 1 (uma) no Maranhão. Atualmente, esta última e 2 (duas) no Espírito Santo estão com a produção paralisada. Considerando as usinas em operação, temos um parque instalado de 691 transportadores de correia totalizando $69,4 \mathrm{~km}$ de correias transportadoras que possuem um valor unitário elevado, sendo assim as correias lideram o ranking de gasto com materiais de manutenção, representando aproximadamente $40 \%$ desses custos. Além disso, considerando que as correias transportadoras possuem um leadtime de fabricação de 120 dias, é necessário manter correias em estoque (alto valor) para demandas emergências e/ou não planejadas e também uma previsibilidade de troca mínima de 120 dias para possibilitar a compra da correia.

\begin{tabular}{|c|c|c|}
\hline \multicolumn{3}{|c|}{ Tabela 1: Parque instalado de correias transportadoras em operação na pelotizaca } \\
\hline Usina & $\begin{array}{c}\text { Quantidade de } \\
\text { Trasnportadores }\end{array}$ & $\begin{array}{c}\text { Parque instalado } \\
(\mathrm{m})\end{array}$ \\
\hline Fábrica & 111 & 6.527 \\
\hline Vargem Grande & 92 & 9.492 \\
\hline Usina 1 & 18 & 4.002 \\
\hline Usina 2 & 10 & 484 \\
\hline Usina 3 (ITA) & 71 & 6.482 \\
\hline Usina 4 (HISP) & 66 & 5.482 \\
\hline Usina 5 (NIB) & 77 & 7.657 \\
\hline Usina 6 (NIB) & 78 & 7.887 \\
\hline Usina 7 (KOB) & 71 & 8.587 \\
\hline Usina 8 & 97 & 12.786 \\
\hline Total Geral & 691 & 69.385 \\
\hline
\end{tabular}

Em condições normais, as correias transportadoras são substituídas apenas por desgaste na região de carga, porém, devido a desvios operacionais, as correias podem ser substituídas por avarias.

Considerando praticamente inviável o cálculo teórico da vida útil de uma correia transportadora devido às diversas variáveis envolvidas nesse processo, citadas na figura 1. 


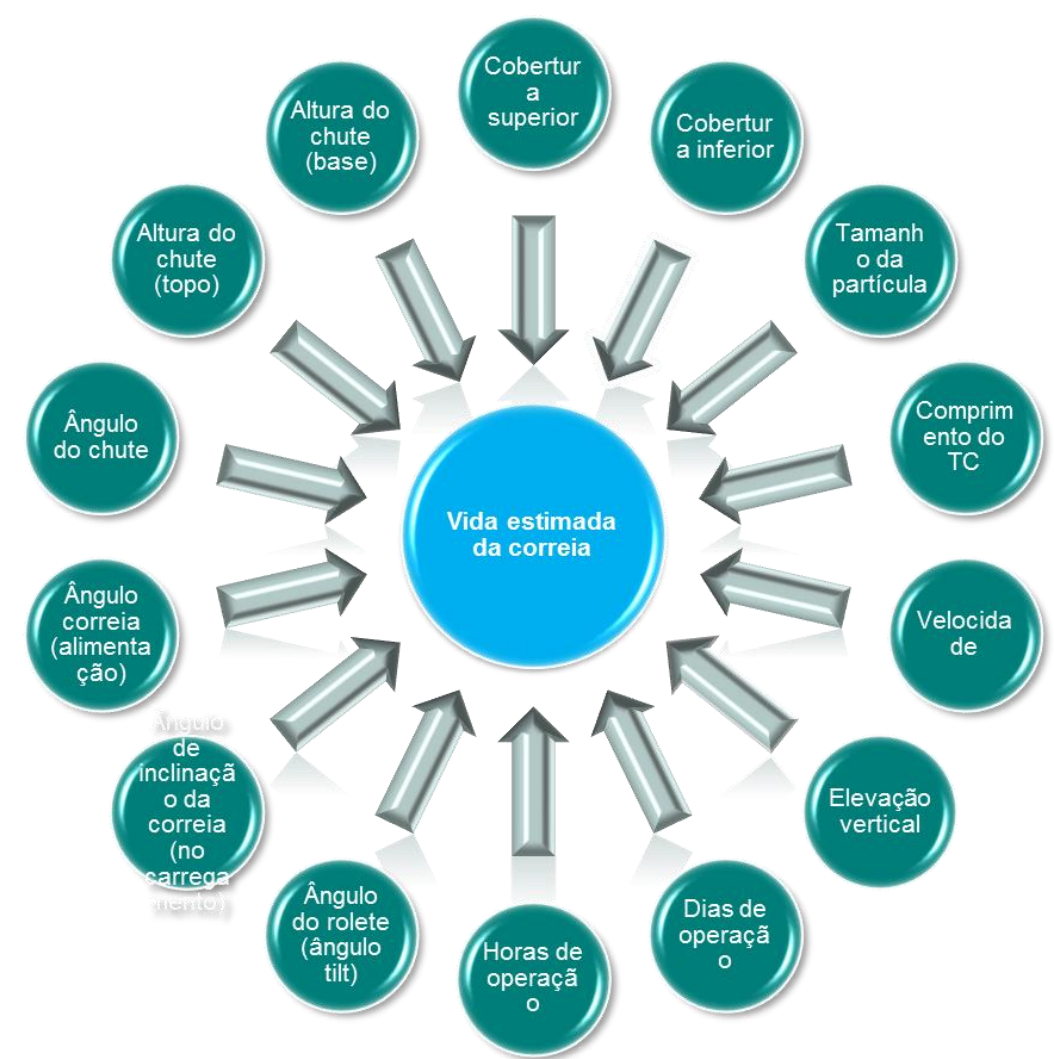

Figura 01: Variáveis no processo de desgaste de correias transportadoras

Diante da importância dos transportadores de correia foi aprimorada a gestão de consumo e custo de correias transportadoras trazendo ganhos na redução de consumo e estoque de correias sem aumentar os riscos operacionais. Mesmo com os avanços significativos nos resultados de consumo e custo de correia na pelotização, ainda temos uma oportunidade de ganho na aderência a previsibilidade de compra da correia com objetivo de manter um estoque equilibrado. Também não é possível afirmar que estamos extraindo o maior valor das correias transportadoras uma vez que não é viável o calculo teórico da vida útil de uma correia; sendo assim através de analises de confiabilidade dos dados de vida e analise de degradação é possível identificar o momento ótimo para troca da correia e definir um estoque com base em risco, que é o ponto de maior resultado operacional.

\section{MATERIAIS E MÉTODOS}

\subsection{GESTÃO DE ATIVOS \& ESTRATÉGIA DE MANUTENÇÃO DA PELOTIZAÇÃO}

A Gestão de Ativos são atividades, práticas sistemáticas e coordenadas pelos quais uma organização gerencia, de forma ótima e sustentável, seus ativos e/ou sistemas de ativos, seu desempenho associado, riscos e custos durante seus ciclos de vida com a finalidade de alcançar seu plano estratégico organizacional [1].

A estratégia de manutenção da Pelotização da Vale é voltada para o negócio. Atua em conformidade às normas técnicas e normas regulamentadoras, gerencia de forma sustentável seus ativos, os desempenhos associados, além dos riscos e os custos ao longo dos seus ciclos de vida com o propósito de atingir o plano estratégico da Vale; também está alinhada às melhores práticas em gestão de ativos. 


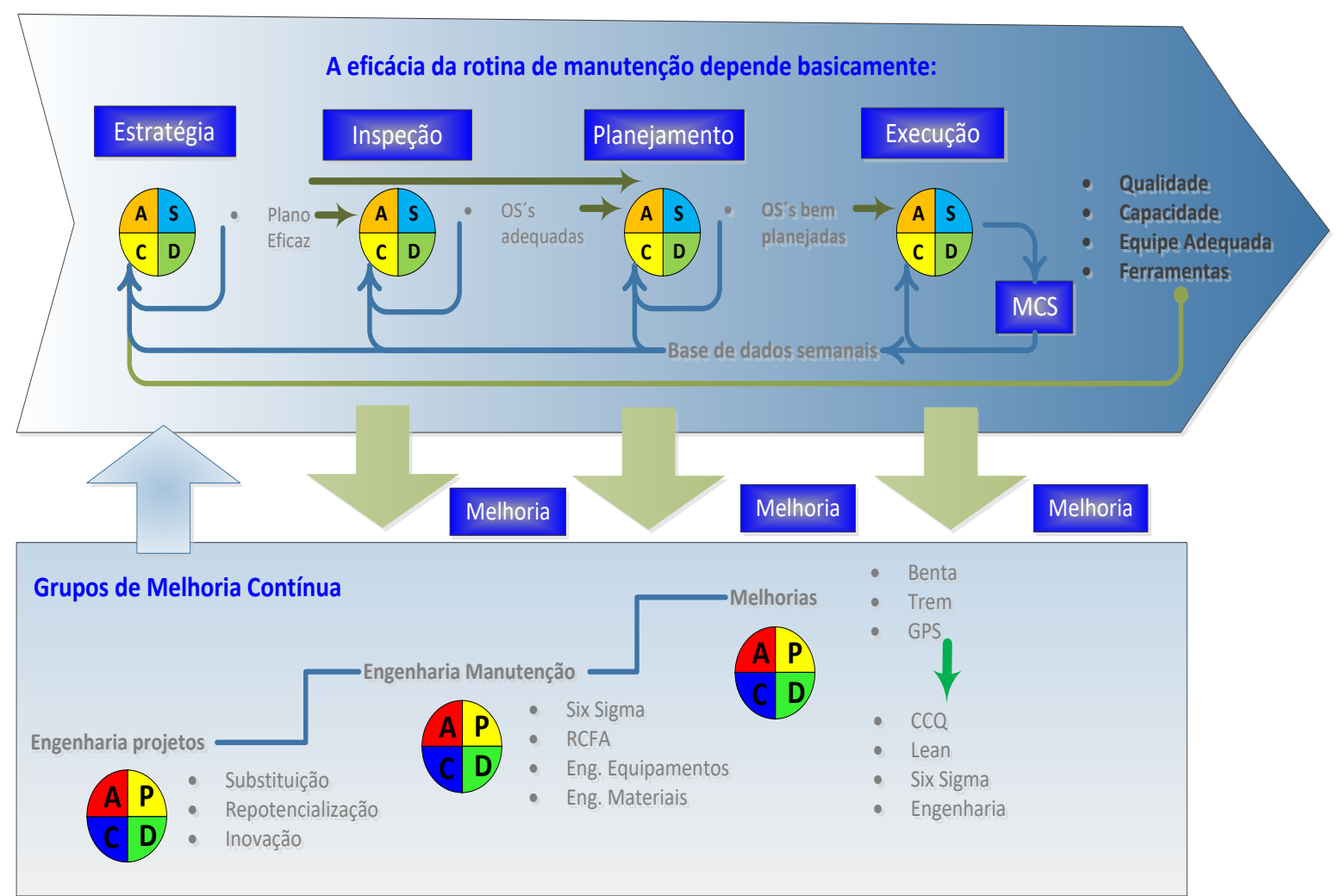

Figura 02: Estratégia Manutenção - Confiabilidade x Custo x Risco

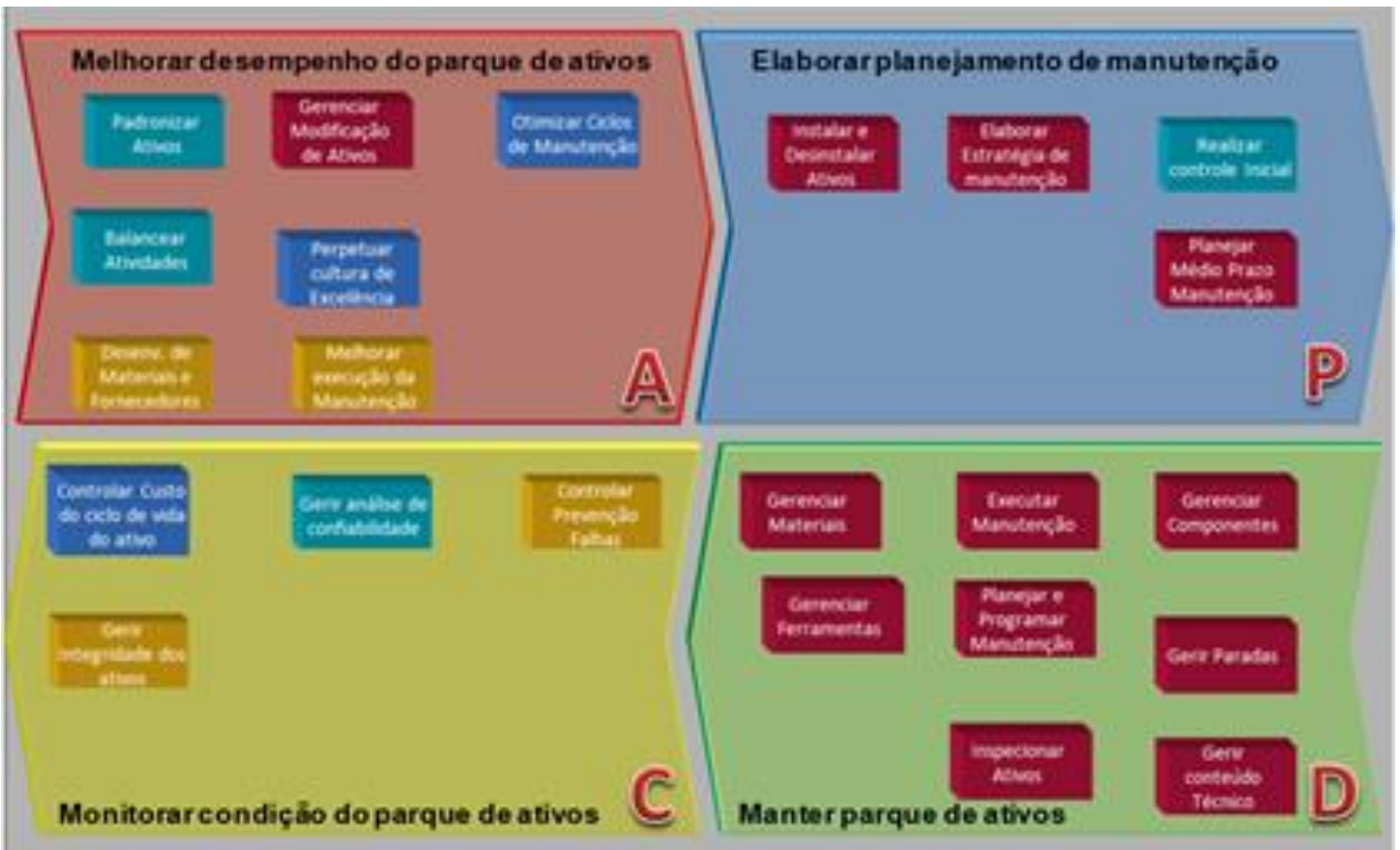

Figura 03: Macroprocesso de gestão de ativos

Alinhado com a estratégia de manutenção foi aprimorado a gestão dos transportadores de correia visando atingir os resultados estratégicos da Pelotização. Nesse processo pode ser destacado a gestão de compra e estoque de correia e a rotina de inspeção das correias transportadoras. 


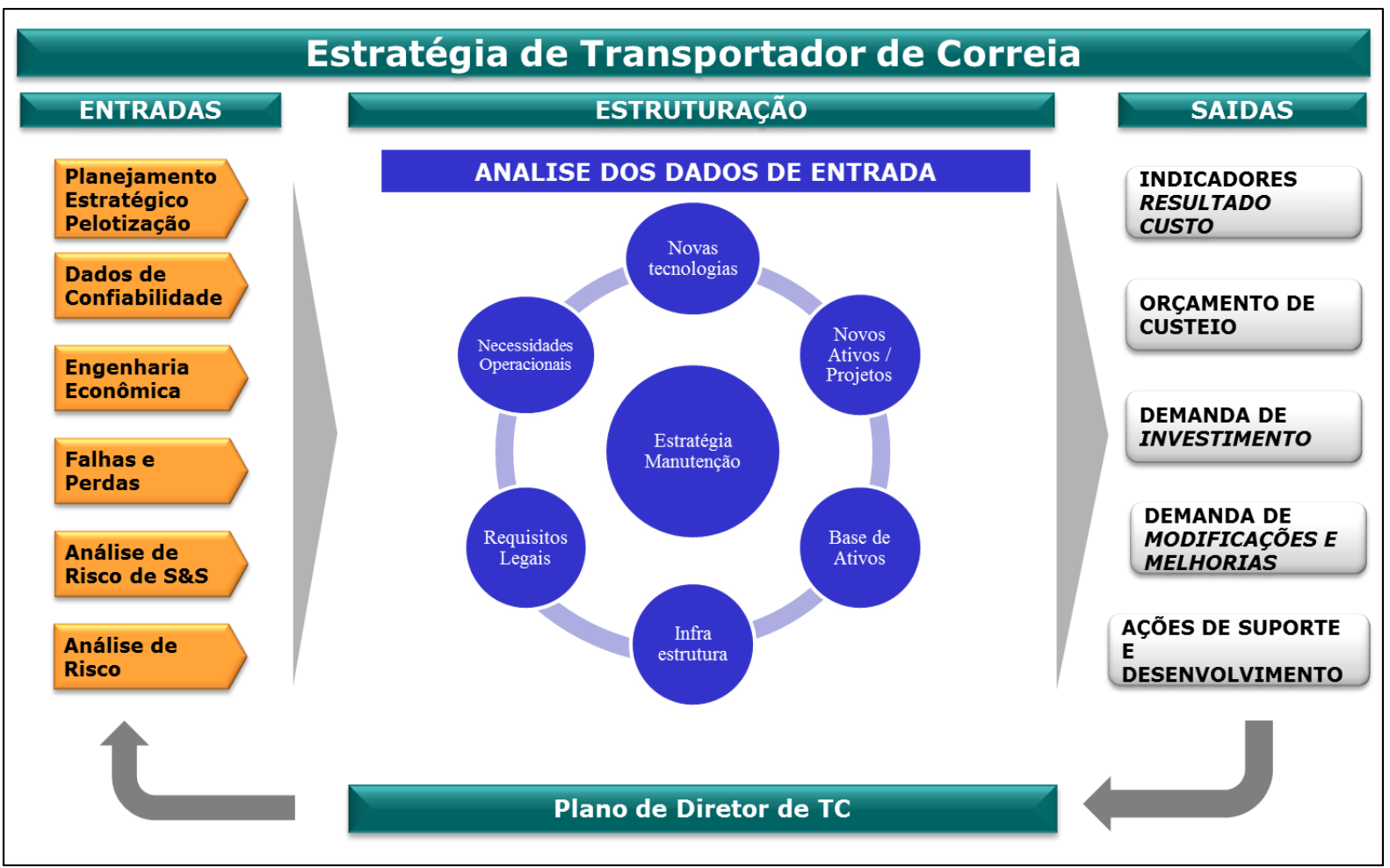

Figura 04: Estratégia Manutenção dos Transportadores de Correia

\subsection{ENGENHARIA DE CONFIABILIDADE}

Engenharia de confiabilidade é a combinação de física, estatística e engenharia em uma única disciplina. A um nível elevado, o propósito do programa da engenharia da confiabilidade é quantificar, testar e reportar a confiabilidade de um produto de uma organização. Essa informação é utilizada para acessar o impacto financeiro da confiabilidade dos produtos e melhorar a confiabilidade geral dos produtos, e consequentemente, a robustez financeira da organização [2].

\subsubsection{ANÁLISE DE DADOS DE VIDA}

Análise de dados de Vida de confiabilidade refere-se ao estudo e modelagem de vidas de produtos observadas. Dados de vida podem ser vidas de produtos no mercado, como o tempo que o produto operou com sucesso ou o tempo que o produto operou antes que falhasse. Todos esses dados da vida útil do produto podem ser abrangidos nos dados de vida do termo ou, mais especificamente, nos dados de vida do produto. A análise e previsão subseqüentes são descritas como análise de dados de vida [3].

No caso das correias transportadoras foi utilizado o histórico de troca de correias que considera todos os modos de falhas conhecidos, são eles: Rasgo longitudinal, avaria na borda, desgaste irregular, desgaste normal (região de carga); avaria na cobertura; avaria no retorno; bolha na cobertura e/ou no retorno, trinca na cobertura e avaria na emenda.

Através desses modos de falhas, foi projetado as curvas de confiabilidade de dois transportadores de correia que possuem características similares de aplicação, função, cargas, velocidade, condições operacionais, etc. 


\subsubsection{PROBABILIDADE DE FALHA VS. TEMPO}

A figura 5 a seguir representa a curva da probabilidade de falhas vs. tempo do transportador 3P2. Para o calculo da probabilidade de falha desse transportador, foram considerados eventos de falhas registrados desde janeira de 2010 até julho de 2016.

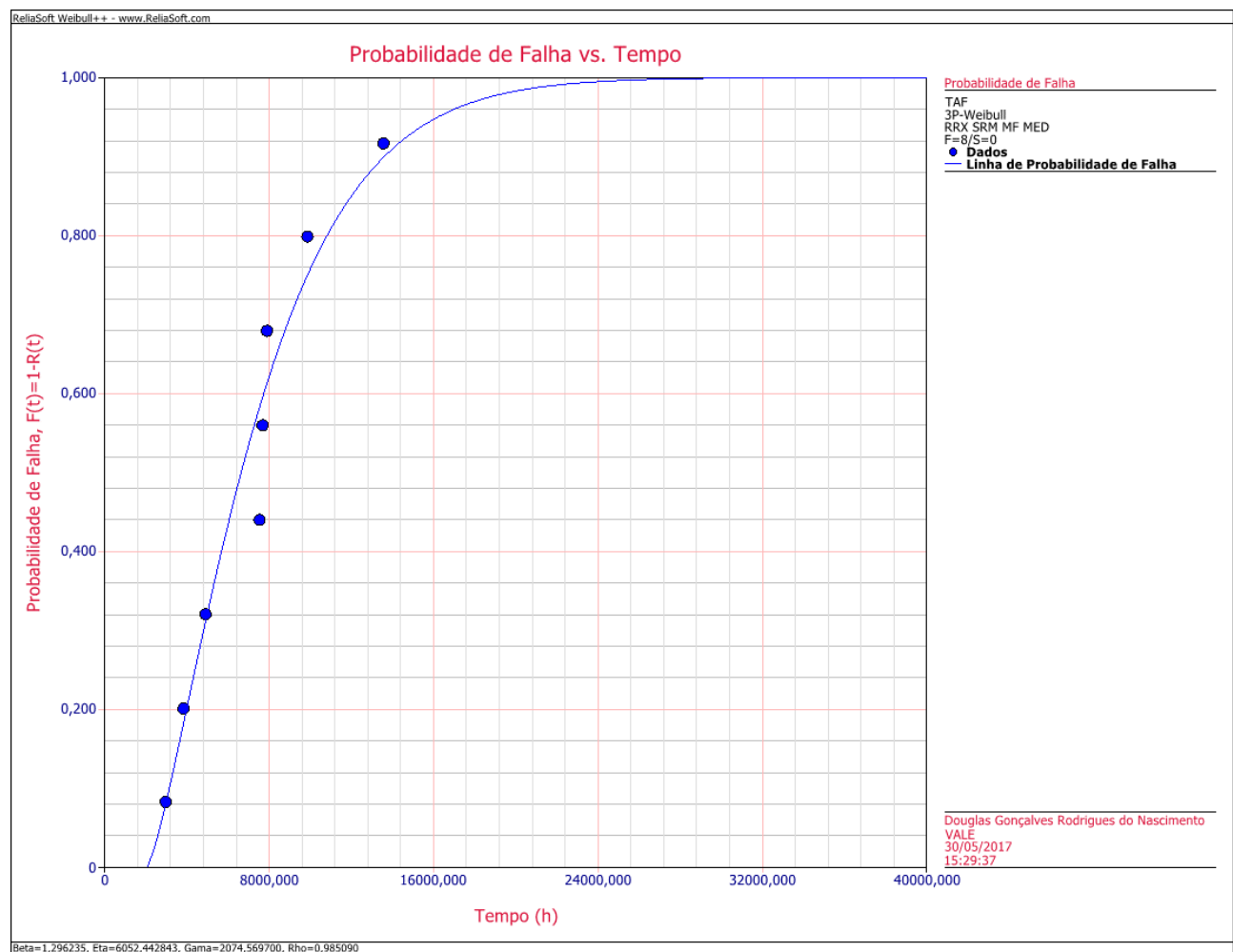

Figura 05 - Probabilidade de falha vs. tempo - transportador 3P2

Considerando todos os modos de falha a vida média calculada do equipamento é de aproximadamente 7667 horas

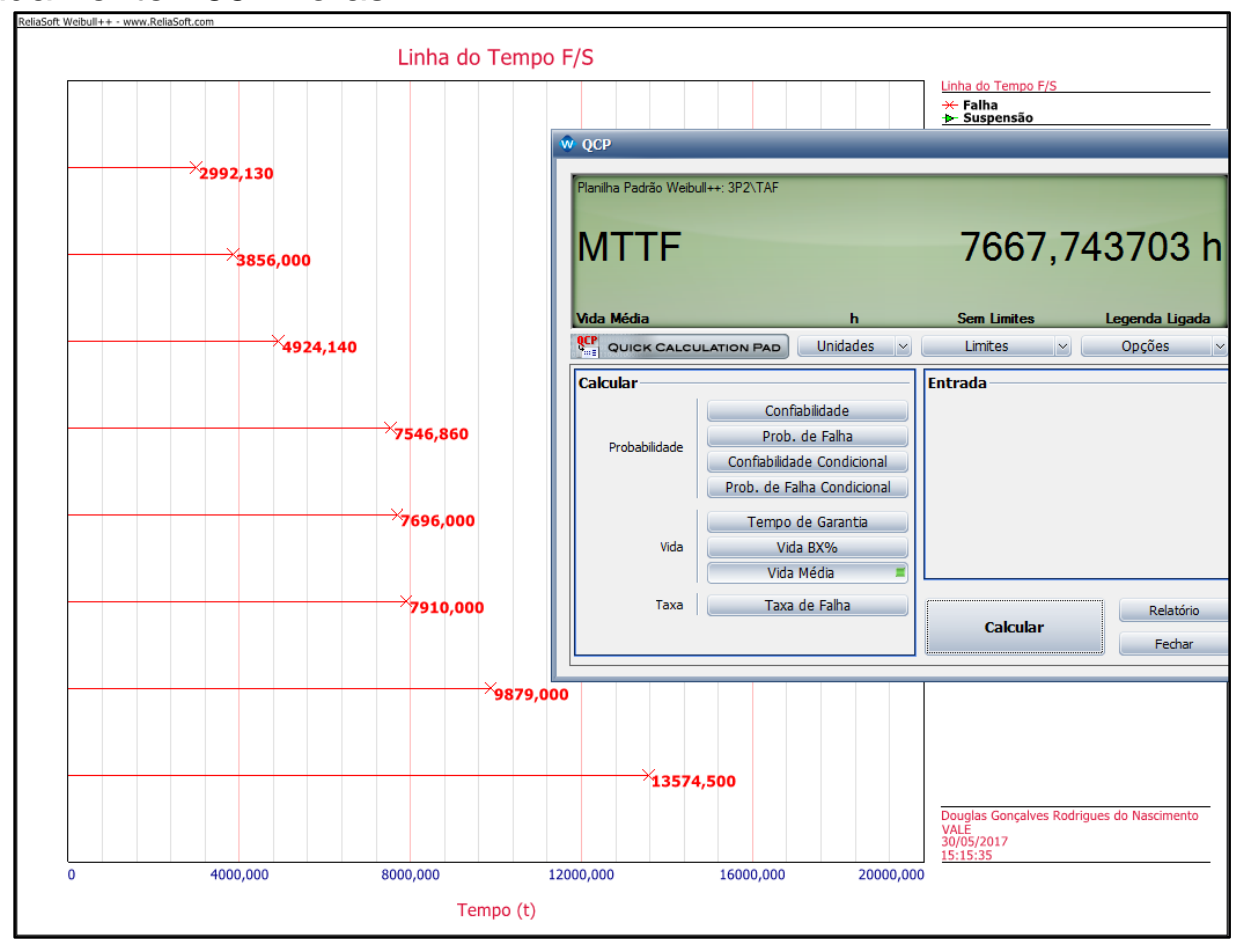

Figura 06 - Tempo médio até a falha - Transportador 3P2 


\subsubsection{ANÁLISE DE DEGRADAÇÃO}

A análise de degradação envolve a medição de dados de desempenho que podem estar diretamente relacionados com a presumida falha do produto em questão. Muitos mecanismos de falha podem estar diretamente ligados à degradação de parte do produto e a análise de degradação permite ao analista extrapolar para um tempo de falha assumido com base nas medições de degradação ao longo do tempo [3]. O comportamento estatístico de desgaste das correias transportadoras é obtido através de dados de medição da espessura diferentes pontos e regiões da borracha. Esses pontos de medição estão distribuídos no transportador conforme figura 07.

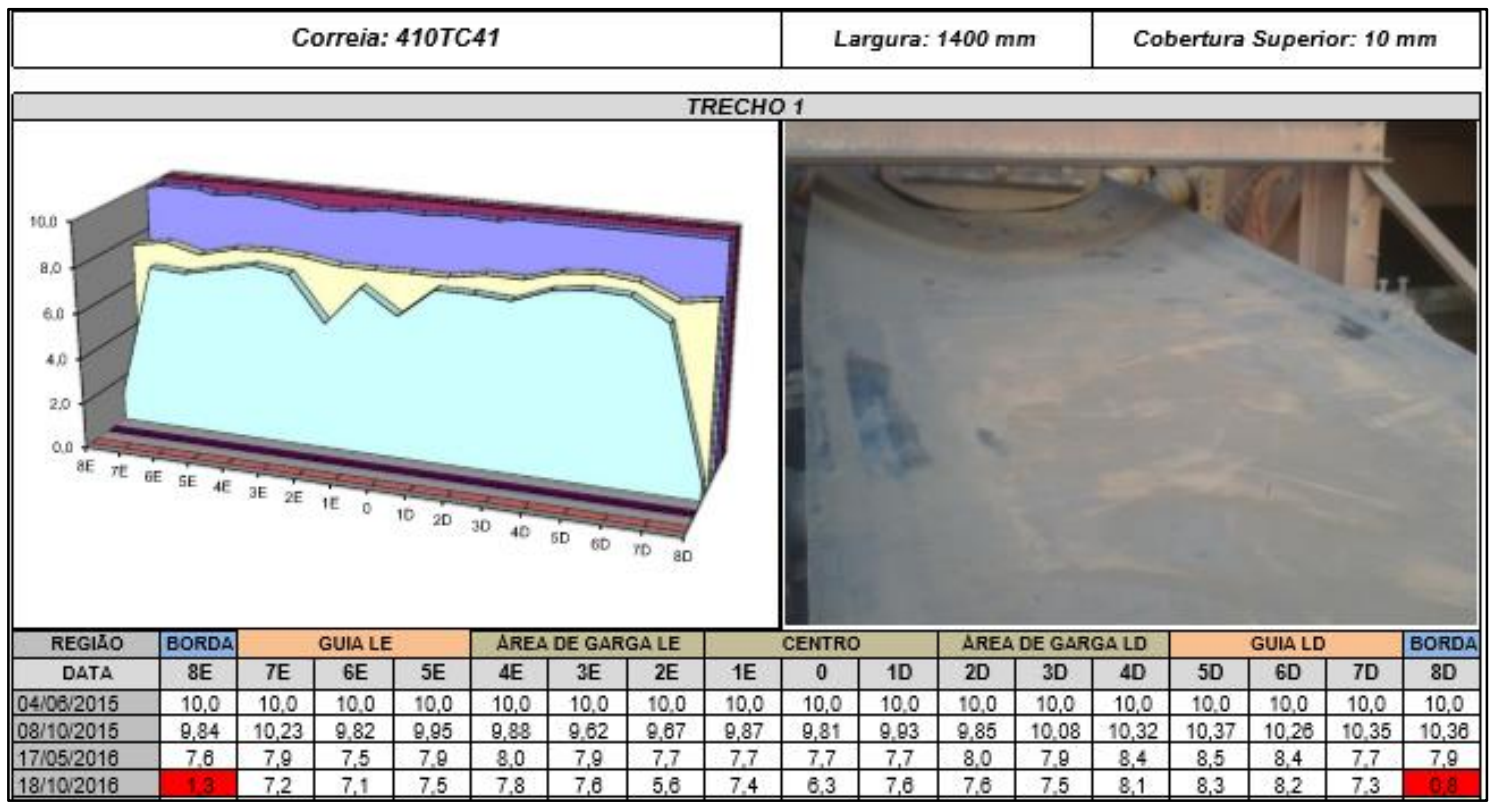

Figura 07: Exemplo de medição da espessura da correia

Com os dados das medições de degradação é possível definir um modelo matemático para realizar a extrapolação da vida do item analisado, e os modelos de extrapolação mais utilizados são:

$$
\begin{gathered}
\text { Linear }: y=a \cdot x+b \\
\text { Exponencial }: y=b \cdot e^{a \cdot x} \\
\text { Potência: } y=b \cdot x^{a} \\
\text { Logaritmo: } y=a \cdot \ln (x)+b
\end{gathered}
$$

Onde $\boldsymbol{y}$ representa $O$ desempenho, $\boldsymbol{x}$ representa o tempo, e $\boldsymbol{a}$ e $\boldsymbol{b}$ são parâmetros dos modelos a serem determinados.

Outros modelos são: Gompertz e Lloyd-Lipow

\subsubsection{DEGREDAÇÃO VS. TEMPO}

Pode ser observado nos dados da figura 07 que os pontos $8 \mathrm{D}$ e $8 \mathrm{E}$, localizados nas bordas do transportador, possuem acentuada degradação e comprometem 0 desempenho esperado da correia. Considerando um limite mínimo de espessura de 
$2 \mathrm{~mm}$ para a região de carga do transportador, a análise de degradação desse transportador apresenta o seguinte comportamento:

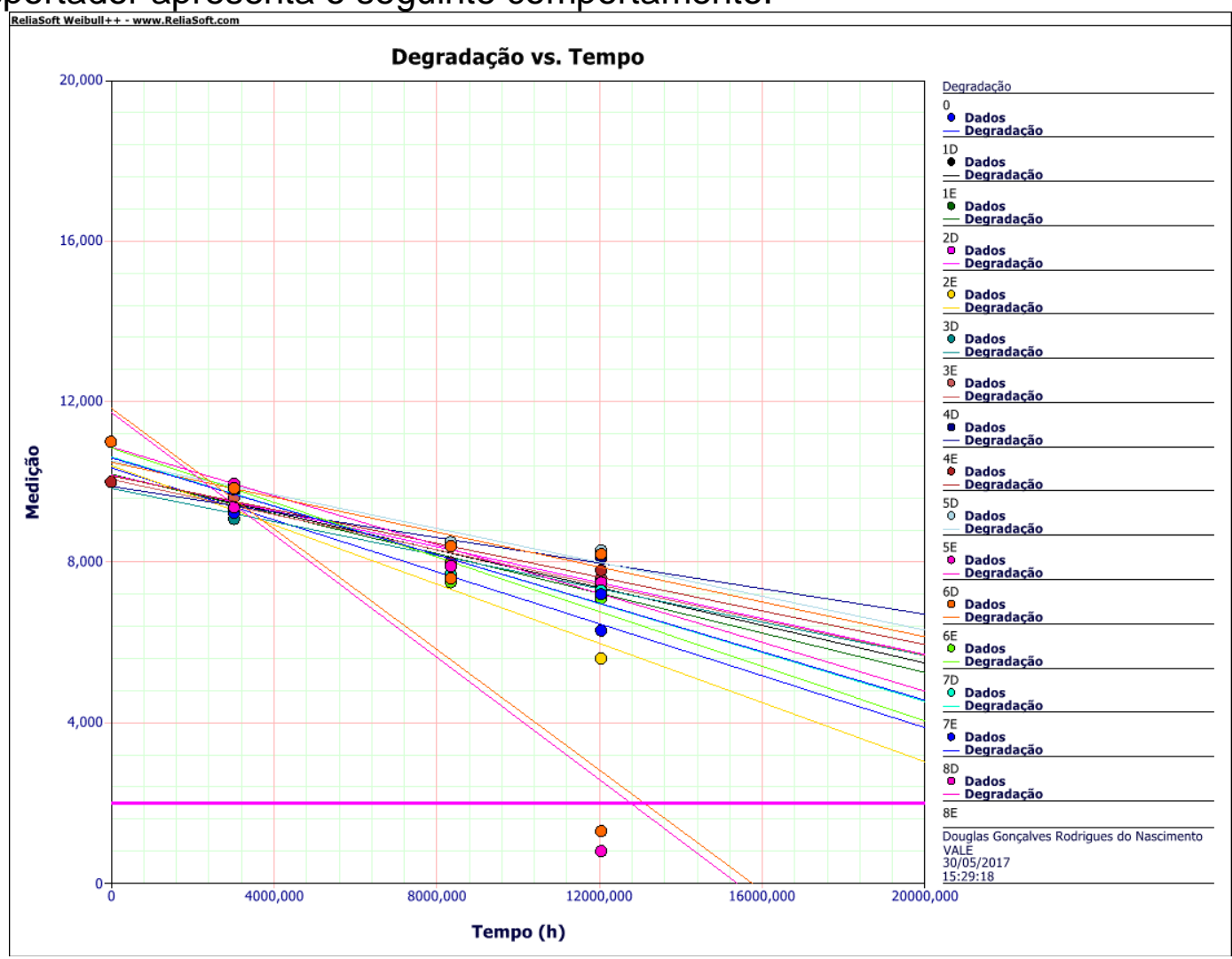

Figura 08 - Degradação vs. Tempo - Transportador 410TC41

Levando em consideração todas as regiões de medição e controle de espessura, a correia possui uma vida útil média de aproximadamente 31097 horas. A curva de degradação média está representada no gráfico da figura 09.

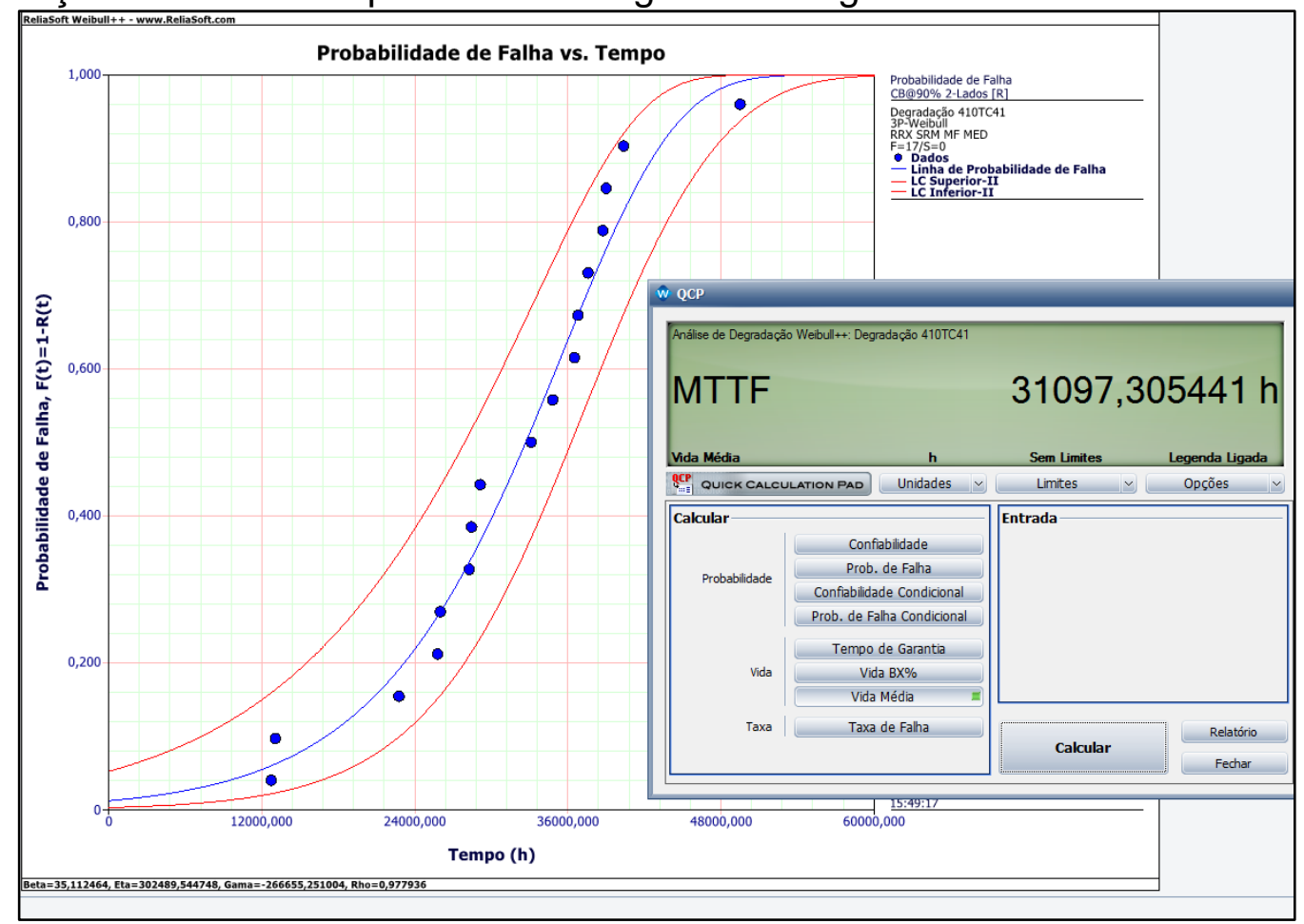

Figura 09- Probabilidade de falha vs. tempo - Transportador 410TC41 
Naturalmente a região central do transportador é a região mais crítica para controle de espessura e avaliação da vida útil. Quando simulado a curva de degradação dessa região, a vida útil projetada alcançaria aproximadamente de 32345 horas.

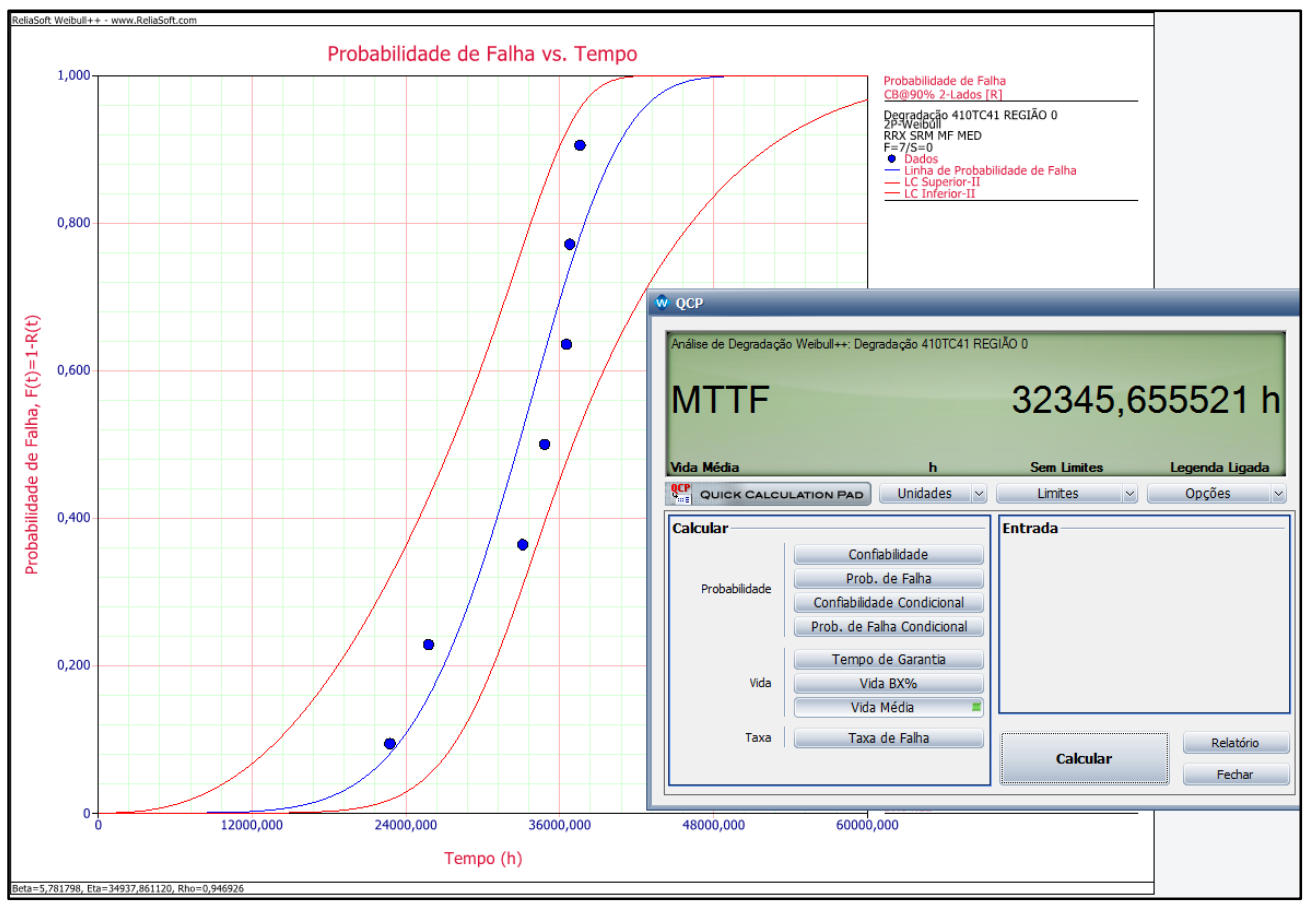

Figura 10 - Probabilidade de falha vs. tempo - região central

\section{RESULTADOS E DISCUSSÃO}

\subsection{EVOLUÇÕES DOS INDICADORES CHAVE DE DESEMPENHO (KPI) DOS TRANSPORTADRES DE CORREIA}

Como resultado da estratégia de manutenção dos transportadores os indicadores chaves de desempenho tiveram uma evolução expressiva dois anos (2015 e 2016). O gasto absoluto de correia foi reduzido em $21 \%$, o gasto específico $(R \$ / t)$ reduziu em $27 \%$ bem como o consumo especifico em $45 \%$. Também foi reduzido o estoque de correia em $28 \%$.

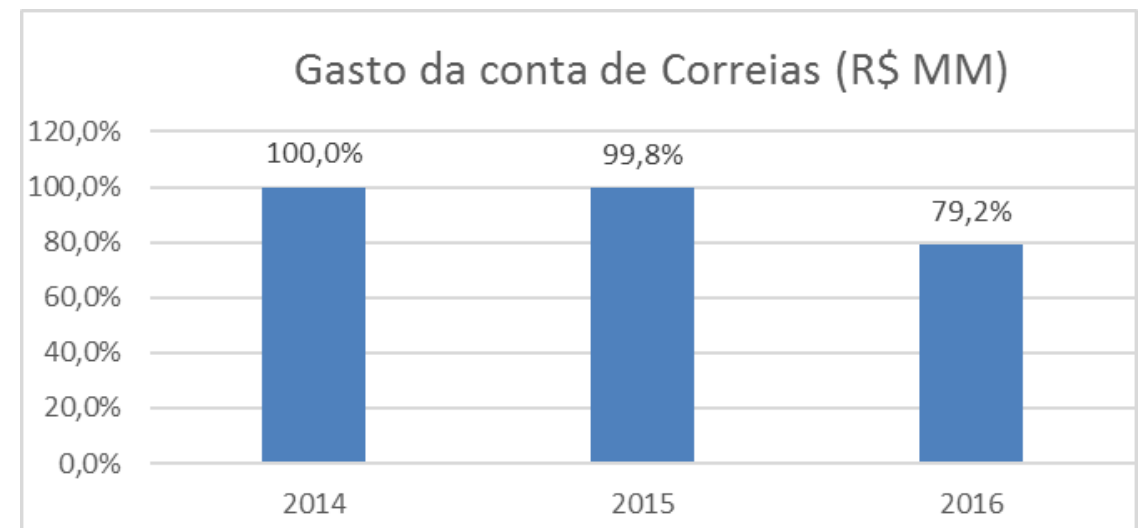

Figura 11: Gasto absoluto com correias transportadoras (R\$MM) 


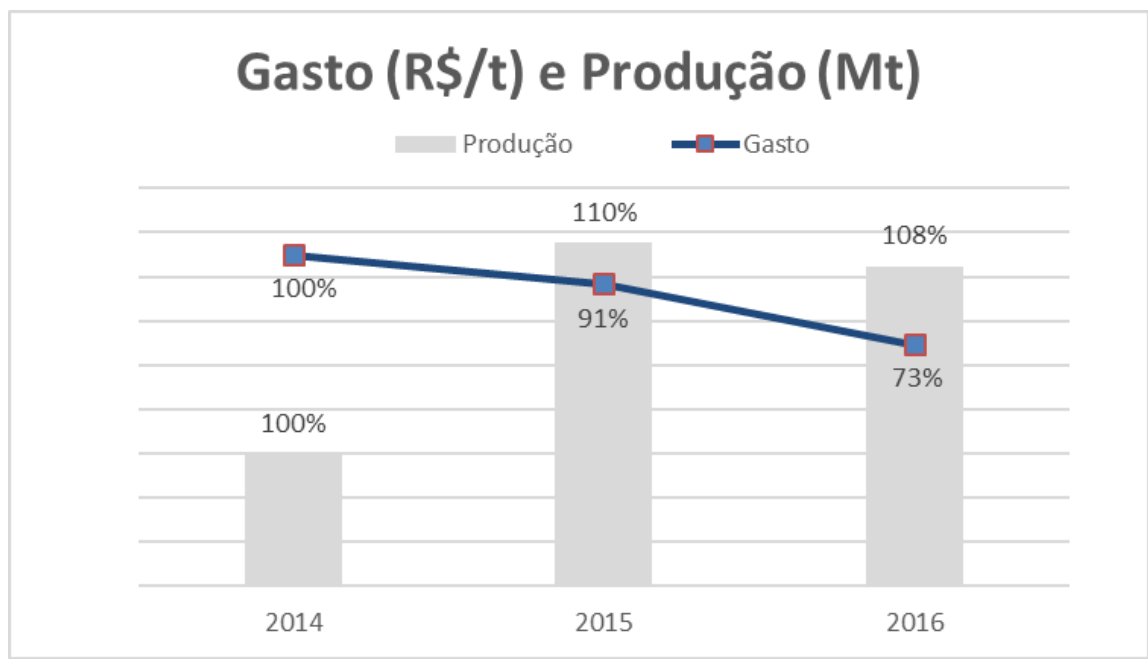

Figura 12: Gasto específico de correia transportadora

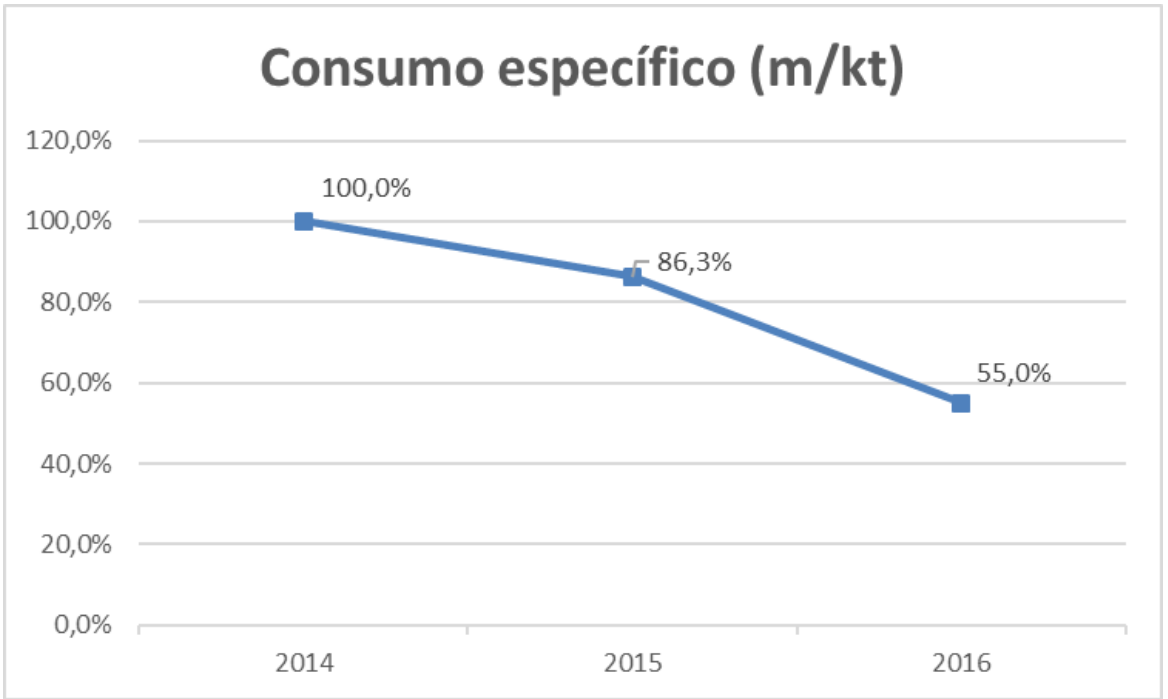

Figura 13: Consumo específico de correia transportadora

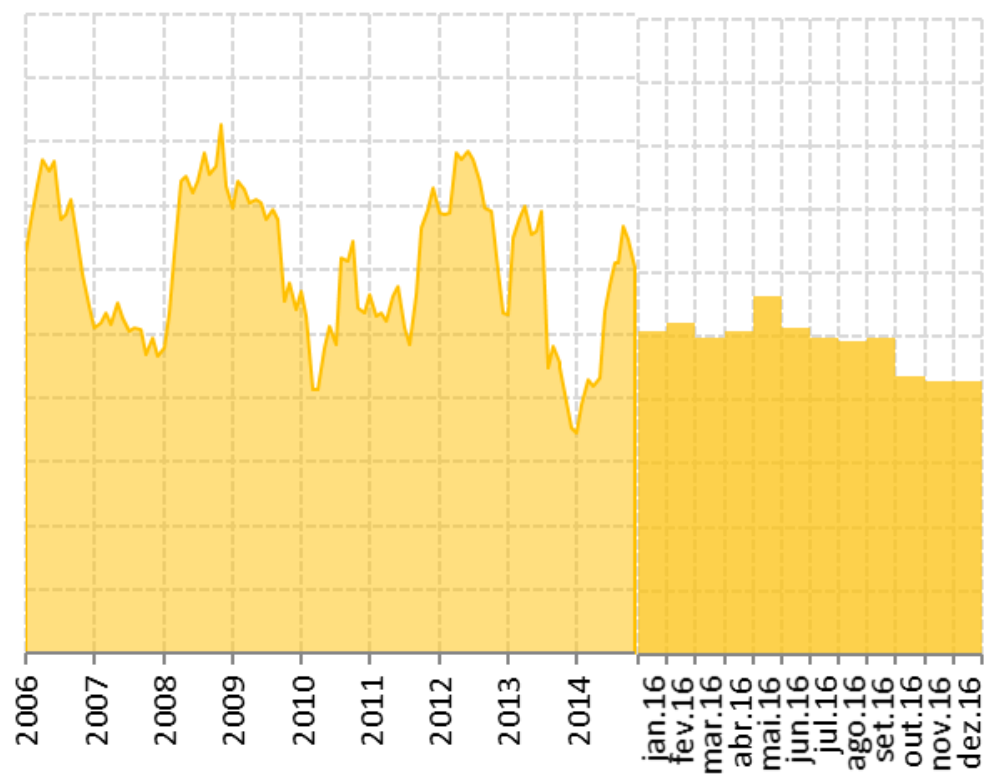

Figura 14: Estoque de correia $(\mathrm{R} \$ \mathrm{MM})$ 


\subsection{ANÁLISES DE DADOS DE VIDA VS. DEGRADAÇÃO}

Com a sobreposição dos gráficos de probabilidade de falha vs. tempo utilizando dados de vida do transportador e degradação considerando dados de medição de espessura da borracha é possível ter uma visão mais ampla das simulações

A figura 15, a seguir, representa essa sobreposição onde a linha azul representa a curva de probabilidade de falha do transportador $3 \mathrm{P} 2$ e foi obtida através da análise de dados de vida do equipamento. A linha de cor preta representada a probabilidade de falha do transportador 410TC41 de aplicação similar ao anterior e foi obtida através da análise de degradação utilizando medições de espessura da borracha do transportador.

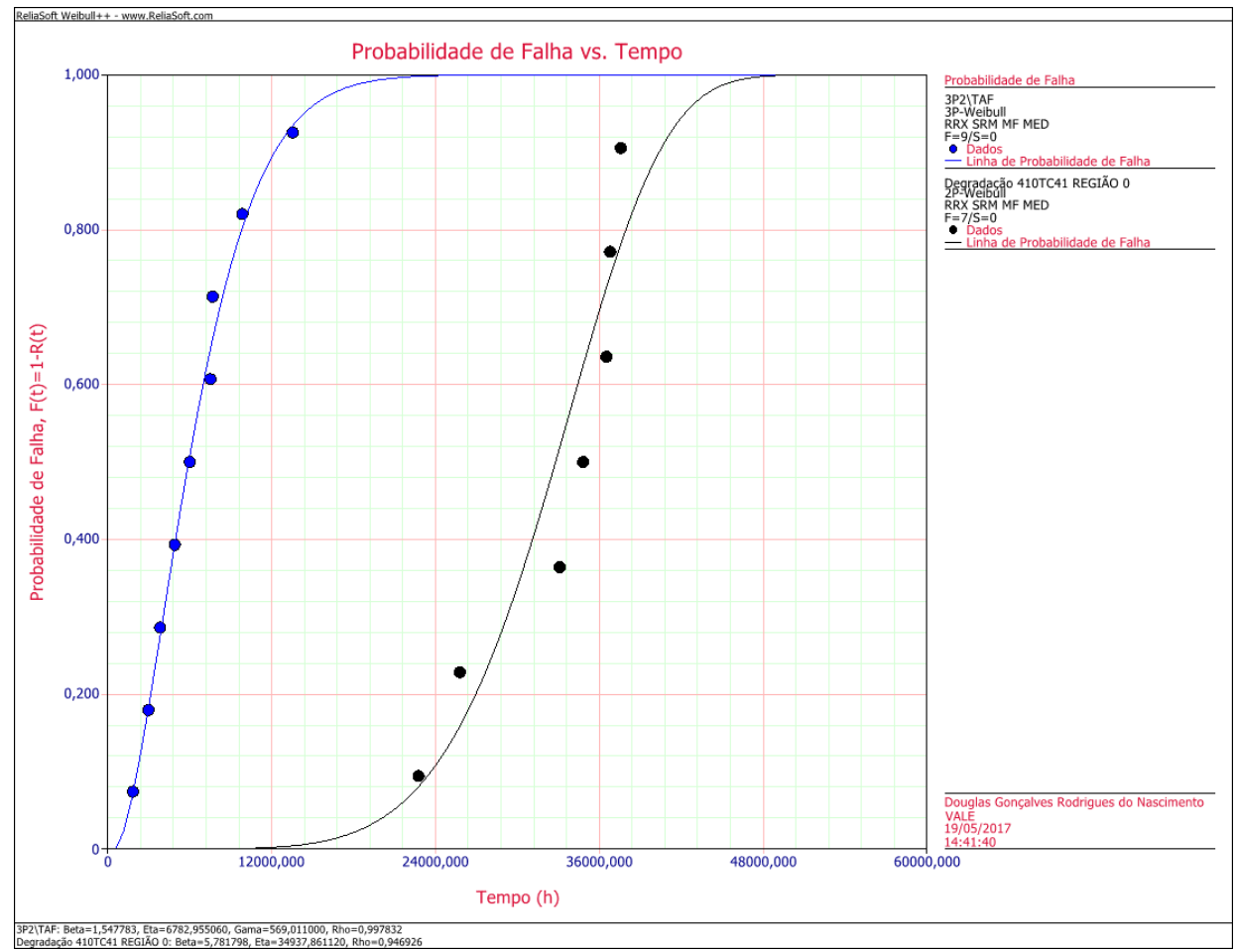

Figura 15 - Gráfico múltiplo - Degradação vs. Dados de vida

\section{CONCLUSÃO}

A estratégia de manutenção aplicada nos transportadores melhorou o retorno sobre o investimento (em inglês, return on investment ou ROI), pois foram reduzidos os custos de manutenção e o valor de estoque. 

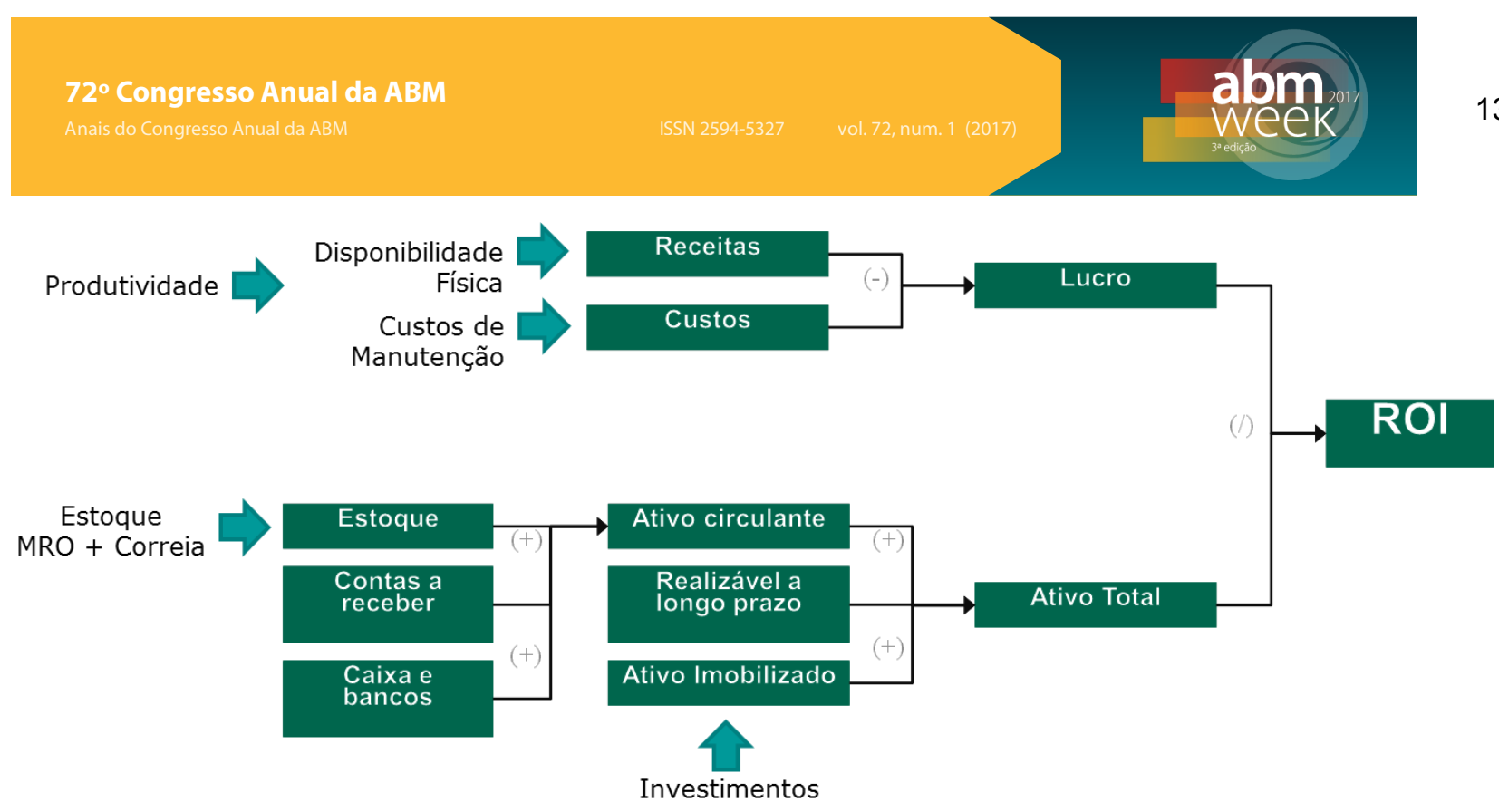

Figura 16 - ROI

De forma clara pode ser observado, na figura 15, o gap de oportunidades na utilização da correia do transportador 3P2 aumentando a vida útil da correia em até quatro vezes. Ou seja, apesar dos ganhos expressivos com a implementação da estratégia voltada par o negocio ainda não estamos extraindo o maior valor das correias transportadoras e engenharia de confiabilidade pode definir as principais oportunidades para atingir esse objetivo.

\section{REFERÊNCIAS}

1 Britsh Standards. Asset Management. PAS 55-1:2008.

2 ReliaSoft. G400 - Engenharia de Confiabilidade: 2016

3 ReliaSoft. M560 - Gestão de Ativos: 2016

4 ReliaSoft Corporation [página da internet]. [acesso em 17 Mai. 2017]. Disponível em: http://www.reliawiki.org/index.php/Main Page

5 Associação Brasileira de Normas Técnicas, ABNT. Gestão de ativos - Visão geral, princípios e terminologia. ABNT NBR ISO 55000:2014.

6 Associação Brasileira de Normas Técnicas, ABNT. Gestão de ativos Sistemas de gestão — Requisitos. ABNT NBR ISO 55001:2014

7 Associação Brasileira de Normas Técnicas, ABNT. Gestão de ativos Sistemas de gestão - Diretrizes para a aplicação da ABNT NBR ISO 55001. ABNT NBR ISO 55002:2014 